\title{
Global Sourcing and Relative Wages with A Nontradable Good
}

\author{
Yong-Yil Choi \\ Hansung University
}

\begin{abstract}
In this paper I introduce a new concept of a global sourcing economy and then investigate the effects of global sourcing on relative wages in a general equilibrium model. From the model I derive the theoretical relative wage equations that show different predictions compared with the existing outsourcing literature. Global sourcing has a negative association with the relative wage of skilled labor to less skilled labor within tradable industry, while it is positively associated with the relative wage of skilled labor to less skilled labor within non-tradable industry. This result is contrasted with the notion that outsourcing is positively correlated with the relative demand for skilled labor. Another finding is that the size of the share of mobile labor used to produce non-traded goods plays a key role in deciding the magnitude of global sourcing effect on the wage inequality within nontradable industry and hence the overall wage inequality.
\end{abstract}

- JEL Classification: F16

- Key Words: Global Sourcing, Relative Wages, Economies of Scale, Nontradable Industry

\section{Introduction}

As the competitive pressures of the global economy increase through the 1990s, an increasing number of firms are combining domestic and international sourcing to win in global markets. Bozarth et al. (1998) define this practice as global sourcing. Thus, a global sourcing economy is emerging as a new concept in

*Corresponding address: Yong-Yil Choi, Professor, Dept. of International Trade, Hansung University, 2389 Samsun-Dong Seongbuk-Gu Seoul Korea 136-792. E-mail address: yychoi8@unitel.co.kr (C)2002-Center for International Economics, Sejong Institution, All Rights Reserved. 
contrast to the traditional concept of a small open economy versus a large open economy. With greater global sourcing, supply chain linkages between firms become more geographically dispersed. This change has affected the structure of demand for labor, because global sourcing not only shifts labor demand across industries, but also does it within industries. It implies important distributional consequences, though there is little research examining the link between global sourcing and relative wages. However, to explain the wage divergence between more-skilled workers and less-skilled workers in the advanced economies, a few papers use outsourcing concept.

Feenstra and Hanson $(1996,1999)$ explore whether outsourcing has contributed to an increase in relative demand for skilled labor. They measure outsourcing as the share of imported intermediate inputs in the total purchase of non-energy materials, and use the non-production-workers share of the industry wage bill to measure the relative demand for skilled labor. Feenstra and Hanson (1996) conclude from their regressions that outsourcing can account for 30.9-51.3 percent of the increase in the non-production wage share occurring in the 1980s. However, Slaughter and Swagel (1997) interpret that Feenstra and Hanson (1996) use the share of inputs to production estimated to come from abroad as the extent of outsourcing production activity to low-wage countries by proxy and argue they do not distinguish the imported intermediate goods as coming from either developing or advanced economies.

On the other hand, as multinational firms have established and/or expanded overseas affiliates, Krugman (1995) explains this trend by saying that it has proved possible to find expanded niches for labor intensive production by slicing up the production of goods traditionally viewed as skill-, capital-, or technology-intensive and putting the labor-intensive slices in low-wage locations. Slaughter (1995) shows that the outsourcing of production can generate the within-industry demand shifts towards skilled labor. He does not consider the "Nike" model of arms-length outsourcing where products are assembled by independent contractors rather than by Nike affiliates, but defines outsourcing to include only intra-firm activity of multinationals and their direct affiliates. He also estimates the factor price elasticity of demand between parent and affiliate labor to test whether these firms substitute heavily between labors in the two locations. The results indicate that home and foreign labor are at best weak substitutes and in fact might be complements. However, through the evidence from Mexicos maquiladoras, Feenstra and Hanson (1997) contend that growth in foreign direct investment is 
positively correlated with the relative demand for skilled labor.

This research is very valuable, but it does not provide a theory of global sourcing on intraindustry relative wage and interindustry relative wage in a general equilibrium framework. Also, the existing literatures in the area are focusing only on the outsourcing activity of advanced economies motivated by low-wage utilization, and hence they disregard the phenomenon that a growing number of firms in domestically owned manufacturing base is combining domestic and international parts.

Therefore, in this paper, I try to build a general equilibrium model that synthesizes the link between global sourcing and relative wages. Global sourcing is defined as net imports of intermediate goods relative to net exports of final goods. Thus, global sourcing here is a more general concept than that of outsourcing, not only because it does not have to distinguish the imported intermediate goods as coming from either developing or developed economies, but also because it does not have to do with whether the activities are kept within the firm. So, this model can provide a theory consistent with Slaughter (2000)'s indication that production transfer does not necessarily increase (and may even decrease) the relative wage for skilled labor. The model also differs from previous works in two other aspects. First, I can derive a direct relationship between relative wages and global sourcing from the general equilibrium framework, so that the misspecification problem on the relationship can be avoided. Second, the model includes a non-tradable sector as Krugman (1995) and Cline (1997) emphasize, so that there are two different (skilled to less-skilled) relative wages: one in tradables and one in nontradables. Hence, the model enables us to explore the issue, whether an increase in global sourcing affects the two relative wages in the same way.

The structure of this paper is as follows. Section II presents a general equilibrium model of global sourcing where there is a tradable final good sector, a tradable intermediate good sector, and a non-tradable final good sector. Firms in the tradable final good sector combine domestic and international sourcing of differentiated intermediate goods. Intermediate goods are produced using only sector-specific skilled labor under increasing returns to scale at firm level. A mobile factor links the tradable good sector and the non-tradable good sector. Thereby global sourcing shifts not only intraindusty relative labor demand, but also interindusty relative labor demand. Section III derives intraindusty and interindusty relative wage equations shaped by four causal variables such as relative global sourcing, factor endowments, the number of foreign intermediate 
goods, and foreign demand for intermediate goods. Based on these causes, comparative static results for the relative wage equations are provided. The results show that an increase in global sourcing affects these two (skilled to less-skilled) relative wages in the different way. This implies that global sourcing has not necessarily a positive association with the relative demand for skilled labor, which is a different prediction compared with the existing outsourcing literature. In this model, an increase in global sourcing can contribute to improve the overall wage inequality, which depends on the share of mobile less-skilled labor used to produce non-traded goods. Since the magnitude of global sourcing impact on the relative wage of skilled labor to less skilled labor within non-tradable industry depends on the share of mobile less-skilled labor used to produce non-traded goods, the share has an important policy implication. Namely, it is highly probable that an economy with a big non-tradable sector experiences distributional conflicts following high intensity of global sourcing. Section IV concludes.

\section{The Model}

Consider an economy with three sectors: tradable final good sector, tradable intermediate good sector, and nontradable final good sector. Assume free trade in final goods, and differentiated intermediate goods. Global sourcing is characterized by trade in differentiated intermediate goods. Further, suppose that no migration of labor is allowed across economies.

There are three factors of production: intermediate good sector specific labor $\left(L_{t s}\right)$, nontradable good sector specific labor $\left(L_{n t s}\right)$, and mobile labor $\left(L_{m}\right)$. The labor markets are competitive. It is assumed that sector specific labor is skilled labor and mobile labor is less skilled labor. We can have two justifications for the assumption. First, the reason why intermediate good sector specific labor is skilled one has to do with monopolistic competition. Since monopolistic competition is assumed in the intermediate good sector, the product of that sector has a market power. And it is usual for skilled labor to have a market premium and thus to be specific to that sector (e.g. computer-chip designers vs computer assembly line workers). Hence, we can assume intermediate good sector specific labor is skilled one. Second, since nontradable good sector specific labor is mostly skilled one in the real world (e.g. medical doctors, professors, barbers etc.), we can safely assume that.

The tradable final good $X$ is produced using not only mobile labor $\left(L_{m}\right)$, but also 
a variety of intermediate goods: $T_{i}, i=1, \ldots,\left(n+n_{f}\right)$, where $n$ is a domestic variety and $n_{f}$ is a foreign variety. Assume $n_{f}$ is exogenously given.

Assuming an aggregate two-stage Cobb-Douglas-CES production function, the production function of good $X$ takes the form,

$$
X=L_{m}{ }^{1-\alpha}\left(\Sigma_{i=1, \ldots, n+n f} T_{i}^{\beta}\right)^{\alpha / \beta}
$$

If $T_{i}$ s are the same for all $i$ in the equation (1), $\left(n+n_{f}\right)^{\alpha / \beta}$ represents external economies of scale. It is assumed that

$$
\begin{gathered}
0<\beta<1 \text { and } 0<\alpha<1, \\
\beta=[1-(1 / \sigma)],
\end{gathered}
$$

where $\sigma=$ the constant elasticity of substitution among the variety of intermediate goods. The value of $\beta$ shows the degree of substitutability among intermediate goods. The lower the $\beta$ is, the more differentiated the intermediate goods are, allowing higher external economies for the tradable final manufactures.

The differentiated intermediate goods are produced using only sector-specific labor $\left(L_{t s}\right)$ under Chamberlinean monopolistic competition, so that the number of intermediate goods produced is large enough to make oligopolistic interaction negligible. There are increasing returns at the level of an individual firm. The production of the $i^{\text {th }}$ intermediate good, $T_{i}$, involves some fixed labor input requirements $\left(z_{o}\right)$ and variable labor input requirements $\left(z T_{i}\right)$ where $z$ represents the constant marginal labor input requirements.

It is assumed that all firms in the intermediate good sector across economies are symmetric. Thus, in equilibrium, all intermediate goods actually produced will be produced in the same quantity and at the same price.

Nontradable good sector specific labor $\left(L_{n t s}\right)$, and mobile labor $\left(L_{m}\right)$ combine to produce nontradable final good $Y$ by the Cobb-Douglas production function which has a different distributive share $\gamma \in(0,1)$. That is, the production function of nontradable final good $Y$ is

$$
Y=L_{m}{ }^{1-\gamma} L_{n t s}{ }^{\gamma}
$$

Suppose both final goods $X$ and $Y$ are produced competitively. Let good $Y$ be the 
numeraire. Then, under free trade the common competitive profit conditions are

$$
\begin{gathered}
P=k\left(n+n_{f}\right)^{-(\alpha / \beta)+\alpha} q^{\alpha} W_{m}{ }^{1-\alpha} \\
1=c W_{n t s}{ }^{\gamma} W_{m}{ }^{1-\gamma}
\end{gathered}
$$

where $k=\alpha^{-\alpha}(1-\alpha)^{\alpha-1} ; c=\gamma^{-\gamma}(1-\gamma)^{\gamma-1} ; p$ is the price of $\operatorname{good} X ; q$ is the price of intermediate goods; $W_{m}$ is the wage rate for mobile labor; and $W_{n t s}$ is the wage rate for nontradable sector specific labor.

The condition for profit maximization in the tradable intermediate good sector is to equate marginal revenue to marginal cost, i.e.

$$
q[1-(1-\beta)]=W_{t s} z
$$

where $W_{t s}$ is the wage rate for intermediate good sector specific labor, and (1- $\beta$ ) is in absolute value the elasticity of the inverse demand for intermediate goods.

Since free entry is assumed, any non-zero profit will be eliminated and in equilibrium:

$$
q T=\left(z_{o}+z T\right) W_{t s}
$$

The mobile and immobile labor market clearing conditions for both tradable sectors are given, respectively, by

$$
\begin{gathered}
k(1-\alpha)\left(n+n_{f}\right)^{-(\alpha / \beta)+\alpha} q^{\alpha} W_{m}{ }^{-\alpha} X+c(1-\gamma) W_{n t s}{ }^{\gamma} W_{m}{ }^{-\gamma} Y=L_{m}{ }^{o} \\
n\left(z_{o}+z T\right)=L_{t s}{ }^{o} \\
c \gamma W_{n t s}{ }^{\gamma-1} W_{m}{ }^{1-\gamma} Y=L_{n t s}{ }^{o}
\end{gathered}
$$

where $L_{m}{ }^{o}$ is the endowment of mobile labor, $L_{t s}{ }^{o}$ is the endowment of intermediate good sector specific labor, and $L_{n t s}{ }^{\circ}$ is the endowment of nontradable sector specific labor.

The national budget constraint is given by

$$
p X+Y=p D_{x}+D_{y}+q H,
$$


where $D_{x}=$ demand for $X ; D_{y}=$ demand for $Y ; H=$ net imports of intermediate goods. $H$ is assumed to be exogenous.

The market clearing condition for nontradable goods is

$$
Y=D_{y}
$$

The world market clearing condition for intermediate goods is

$$
\left(n+n_{f}\right) T_{d}+\left(n+n_{f}\right) T_{d}^{f}=\left(n+n_{f}\right) T,
$$

where $T_{d}=$ the home usage of each intermediate product; $n_{f}=$ the number of foreign intermediate goods; $T_{d}^{f}=$ the foreign usage of each intermediate product. $T_{d}^{f}$ and $n_{f}$ are assumed to be exogenous.

Denote net exports of good $X$ as $E$ that is assumed to be exogenous. Then,

$$
p X=p D_{x}+p E
$$

This implies the quantities (net imports of intermediates and net exports of final goods) are taken as exogenous, and the prices are endogenously solved for. In other words, the model mechanizes such a characteristic of the global sourcing economy that it is the intensity of global sourcing relative to real trade balance has an impact on commodity terms-of-trade, $p / q$, which then affects factoral terms-oftrade.

To complete the model tradable-nontradable final good expenditure constraints are needed. As the production specifications indicate, the relative share $\alpha$ out of the tradable final-good income is spent on the home demand for intermedeate goods, and the relative share 1- $\gamma$ out of the nontradable final-good income goes to the wage bill for the mobile labor employed at nontradable industry. That is,

$$
\begin{aligned}
& \alpha p X=q\left(n+n_{f}\right) T_{d} \\
& (1-\gamma) Y=\delta W_{m} L_{m}{ }^{o}
\end{aligned}
$$

where the share of mobile labor used to produce non-traded goods, $\delta$, is an endogenous variable such that $0<\delta<1$.

Therefore, thirteen independent equations (3)-(15) will determine the value of 
thirteen endogenous variables: $p, W_{m}, W_{t s}, W_{n t s}, q, T, T_{d}, X, Y, D_{x}, D_{y}, n, \delta$.

\section{Intraindustry and Interindustry Relative Wages}

The solutions of the model yield the following equations of relative wages in reduced form:

$$
\begin{gathered}
\frac{W_{t s}}{W_{m}}=k^{\frac{1}{1-\alpha}}\left(\frac{(1-\beta) L_{t s}^{o}}{z_{o}}+n_{f}\right)^{\frac{\alpha(1-\beta)}{(\alpha-1) \beta}}\left(\frac{\beta}{z}\right)\left(\frac{H}{E}\right)^{\frac{1}{\alpha-1}} \\
\frac{W_{n t s}}{W_{m}}=\left(\frac{L_{m}^{o}}{L_{n t s}^{o}}\right)\left(\frac{\gamma}{1-\gamma}\right)\left[1-k^{\frac{1}{1-\alpha}} \frac{(1-\alpha)}{\alpha}\left(\frac{\beta}{(1-\beta)} \frac{z_{o}}{z}-T_{d}^{f}\right) \frac{\left(\frac{(1-\beta) L_{t s}^{o}}{z_{o}}+n_{f}\right)^{\Omega}}{L_{m}^{o}}\left(\frac{H}{E}\right)^{\frac{1}{\alpha-1}}\right] \\
\frac{W_{t s}}{W_{n t s}}=\frac{k^{\frac{1}{1-\alpha}}\left(\frac{(1-\beta) L_{t s}^{o}}{z_{o}}+n_{f}\right)^{\frac{\alpha(1-\beta)}{(\alpha-1) \beta}}\left(\frac{\beta}{z}\right)\left(\frac{H}{E}\right)^{\frac{1}{\alpha-1}}}{\left(\frac{L_{m}^{o}}{L_{n t s}^{o}}\right)\left(\frac{\gamma}{1-\gamma}\right)\left[1-k^{\frac{1}{1-\alpha}} \frac{(1-\alpha)}{\alpha}\left(\frac{\beta}{(1-\beta)} \frac{z_{o}}{z}-T_{d}^{f}\right) \frac{\left(\frac{(1-\beta) L_{t s}^{o}}{z_{o}}+n_{f}\right)^{\Omega}}{L_{m}^{o}}\left(\frac{H}{E}\right)^{\frac{1}{\alpha-1}}\right]}
\end{gathered}
$$

where $\Omega=\frac{\alpha}{(\alpha-1)} \frac{(1-\beta)}{\beta}+1$.

As eqs. (16), (17), and (18) indicate, the exogenous variables to determine relative wages are (H/E), $L_{m}{ }^{o}, L_{t s}{ }^{o}, L_{n t s}{ }^{o}, n_{f}$, and $T_{d}^{f}$. Here, H/E indexes the relative global sourcing that counts the intensity of trade dependency. That is, if net imports of intermediate goods in the home country grow faster than net exports of final goods, the measure of relative global sourcing will pick this up as high intensity of global sourcing by domestic firms with the rest of the world.

Let $I a=$ the natural $\log$ of $\left(W_{t s} / W_{m}\right)$. Let $I b$ be the natural log of $\left(W_{n t s} / W_{m}\right)$, and let $I c$ be the natural $\log$ of $\left(W_{t s} / W_{n t s}\right)$. If wage inequality is measured as the log of relative wage, then $I a$ is the wage inequality between intermediate good sector 
specific labor and mobile labor, and $I b$ is the wage inequality between nontradable final good sector specific labor and mobile labor. Since they measure the wage inequality resulting from intraindustry activity, we can call them intraindustry wage inequality functions. Also, $I c$ is the wage inequality between tradable intermediate good sector specific labor and non-tradable final good sector specific labor, which can be defined as interindustry wage inequality function.

A comparative static exercise from eqs. (16)-(18) gives the theoretical effect of each exogenous variable on the wage inequality. To identify this, take the natural $\log$ of both sides of each relative wage equation and totally differentiate it. Then, each equation is transformed into the type of relative change in variables as in (19)- (21) of the Appendix. $A^{\wedge}$ over variable indicates the relative change in that variable. For example, $\left(\hat{W}_{t s} / W_{m}\right)=d\left(W_{t s} / W_{m}\right) /\left(W_{t s} / W_{m}\right)$, the relative change in the wage inequality between intermediate good sector specific labor and mobile labor.

As (19)- (21) of the Appendix indicate, an increase (decrease) in relative global sourcing $(H / E)$ leads to a decrease (increase) in the relative wage of skilled labor to less skilled labor within tradable industry. This is because a greater global sourcing causes the tradable industrys demand for mobile labor to increase, while it causes the demand for intermediate good sector-specific labor to decrease.

Also, from (15), we know that the output of non-tradable industry increases following an increase in global sourcing, since $[\partial \delta / \partial(H / E)]>0$, and $\left[\partial W_{m} / \partial(H / E)\right]$ $>0$. This can be supported by the fact that as the economic globalization increases, the service sector tends to expand. Furthermore, under the situation that tradable final good sector competitively bids for mobile labor following an increase in global sourcing, for the output of non-tradable industry to increase the wage rate for non-tradable sector specific labor should increase. Due to the magnification effect on non-tradable output by $1 /(1-\gamma)$, the increase of $W_{n t s}$ will be greater than that of $W_{m}$. Thus, an increase (decrease) in relative global sourcing $(H / E)$ leads to an increase (decrease) in the relative wage of skilled labor to less skilled labor within non-tradable industry. Therefore, we now have the following proposition:

Proposition 1. A greater global sourcing results in a reduction of the within tradable industry wage inequality and an increase of the within non-tradable industry wage inequality.

Proposition 1 makes a contrast with the finding of the major outsourcing literature, which demonstrates simply a larger outsourcing causes wage divergence. This is because outsourcing is defined as displacement of relatively 
unskilled labor intensive activity from developed countries. However, global sourcing is an activity to combine the most competitive parts globally without regard to relative skill intensity. Thus, an increase in global sourcing would tend to increase relative price of final goods. In the model here, since $H / E=p / q$, an increase in relative global sourcing $(H / E)$ leads to the increase in $W_{m}$ through the relationship between product and factor price, but the magnification effect on nontradable output causes the two different (skilled to less-skilled) relative wages to change in the different way. This results in the different implication that the intensity of global sourcing can contribute to reduce the overall wage inequality.

Then, under what condition can an increase in global sourcing improve the overall wage inequality? The answer has to do with the magnification effect of global sourcing on wage inequality. As presented in (19)-(21) of the Appendix, both relative change in the within tradable industry wage inequality $(I a)$ and relative change in the interindustry wage inequality (Ic) are magnified due to relative change in global sourcing, while relative change in the wage inequality within non-tradable industry $(I b)$ can be either magnified or not, which depends on the size of the share of mobile labor used to produce non-traded goods $(\delta)$. That is, from (20), we can get the following proposition:

Proposition 2. If the share of mobile labor used to produce the non-traded good $(\delta)$ is not lager than a half, then relative change in the wage inequality between non-tradable final good sector specific labor and mobile labor is magnified following relative change in global sourcing.

In Proposition 2, $\delta \leq 0.5$ means that non-tradable industry does not use intensively mobile labor. And the share of mobile labor used to produce nontraded goods $(\delta)$ is the only channel for global sourcing to affect the relative wage of non-tradable industry via the interindustry movement of less skilled labor. So, under the condition $\delta \leq 0.5$, the non-tradable output magnification due to global sourcing change has a greater impact on the non-tradable sector specific labor share of the industry wage bill. Thus, if $\delta \leq 0.5$, a change in global sourcing magnifies the wage inequality of skilled to less skilled labor within non-tradable industry. Proposition 2 suggests that there is a critical value of $\delta$ giving rise to a distributional conflict. This implies that if an economys service sector is large relative to other sectors, policy makers should pay attention to the value of $\delta$ to reduce globalization tension.

The impact of labor endowment change on its own relative wage is regular as expected. That is, an increase in each labor supply such as $L_{t s}{ }^{o}, L_{n t s}{ }^{o}, L_{m}{ }^{o}$ leads to 
a decrease in the corresponding relative wage expressed in eqs. (19)-(21) of the Appendix. However, as presented in (20)-(21) of the Appendix, the impact of $L_{t s}{ }^{o}$ on the relative wage of non-tradable sector specific labor is not clearly determined. Namely, it depends on many factors such as the relative share in total tradable final output $(\alpha)$, the degree of substitutability among intermediate goods $(\beta)$, the share of mobile labor used to produce non-traded goods $(\delta)$, and the relative share of home variety out of total number of intermediate goods. For example, relative change in the wage inequality within non-tradable industry $(I b)$ is negatively associated with relative change in tradable sector specific labor endowments if and only if $1>[\alpha /(1-\alpha)] /[\beta /(1-\beta)]$.

Relative change in the wage inequality within tradable industry $(I a)$ is negatively associated with relative change in the number of foreign variety $\left(n_{f}\right)$, as presented in (18). To explain this, suppose $n_{f}$ has increased. Then, external economies of scale happen in tradable final good sector, which increases the productivity of mobile labor. It causes the wage rate of mobile labor to rise. But the external economies of scale lower the wage rate of intermediate good sectorspecific labor through the contraction of intermediate good price. On the other hand, the impact of $n_{f}$ on $I b$ or $I c$ depends on the value of $\Omega$ Therefore, we can get

Proposition 3. External economies of scale due to foreign innovations reduce the within tradable industry wage inequality, while its impact on the within non-tradable industry wage inequality depends on the relative share in total tradable final output $(\alpha)$ and the degree of substitutability among intermediate goods $(\beta)$.

Finally, relative change in the wage inequality within non-tradable industry (Ib) is positively associated with relative change in foreign demand for each intermediate product $\left(T_{d}^{f}\right)$. This is because an increase (decrease) in $T_{d}^{f}$ causes $T_{d}$ to decrease (increase) via (12), which results in the decline (increase) of demand for mobile labor in tradable final good industry and thus the fall (rise) of $W_{m}$. For example, the sudden increase in foreign demand for D-ram chips will cause a costpush in tradable final good industry. But the decline (increase) of demand for mobile labor in tradable final good industry causes $\delta$ to rise (fall), which leads to an increase (decrease) in the productivity of non-tradable good sector specific labor. Hence, we now get:

Proposition 4. Foreign demand boom for intermediate products causes the wage inequality within non-tradable industry to rise. 
Table 1. The comparative static results on relative wages

\begin{tabular}{|c|c|c|c|}
\hline \multirow{2}{*}{ Change } & \multicolumn{3}{|c|}{ Effect on the wage inequality } \\
\cline { 2 - 4 } & $I a$ & $I b$ & $I c$ \\
\hline $\begin{array}{c}\mathrm{E} / \mathrm{H} \\
\text { or }(\mathrm{H} / \mathrm{E})\end{array}$ & $\begin{array}{c}(-) \\
L_{t s}{ }^{o}\end{array}$ & - & + \\
\hline$L_{n t s}{ }^{o}$ & None & $-*$ & $-{ }^{* *}$ \\
\hline$L_{m}{ }^{o}$ & None & + & + \\
\hline$n_{f}$ & - & $-*$ & - \\
\hline$T_{d}^{f}$ & None & + & $-* *$ \\
\hline
\end{tabular}

Notes: + indicates positive association; - indicates negative association; $*$ holds if and only if $1>[\alpha /(1-$ $\alpha)] /[\beta /(1-\beta)]$; ** holds if $1>[\alpha /(1-\alpha)] /[\beta /(1-\beta)]$; Notation is explained in the text.

The findings in this section are summarized in the Table $\mathbf{1}$.

\section{Conclusion}

In this paper I have introduced a new concept of a global sourcing economy and examined the effects of global sourcing on relative wages. To do this I built a general equilibrium model that synthesizes the link between global sourcing and relative wages. From the model I derived the theoretical relative wages equations shaped by four causal variables such as relative global sourcing, factor endowments, the number of foreign intermediate goods, and foreign demand for intermediate goods. The comparative static exercises based on these variables have shown that the global sourcing model has different results compared with the prediction of the existing outsourcing literature.

The major findings are as follows: First, a greater global sourcing results in a reduction of the within tradable industry wage inequality and an increase of the within non-tradable industry wage inequality; Second, there is a critical value of the share of mobile labor used to produce non-traded goods giving rise to distributional conflicts following global sourcing; Third, external economies of scale due to foreign innovations reduce the within tradable industry wage inequality, while its impact on the within non-tradable industry wage inequality depends on the relative share in total tradable final output and the degree of substitutability among intermediate goods; Fourth, foreign demand boom for intermediate products causes the wage inequality within non-tradable industry to 
rise.

Therefore, from the results, we can obtain not only a theory consistent with the possibility that an increase in global sourcing improves the overall wage inequality, but also the identification of four causal variables to help avoiding the misspecification problem in the future empirical studies.

\section{Acknowledgement}

This research was financially supported by Hansung University in the year of 2002.

Received 15 March 2001, Accepted 22 October 2001

\section{References}

Bozarth, C., Handfield, R. and Das, A. (1998), "Stages of Global Sourcing Strategy.

Evolution: An Exploratory Study," Journal of Operations Management 16, 241-255.

Cline, W. R. (1997), Trade and Income Distribution, Washington, DC:IIE.

Feenstra R.C. and Hanson, G.H. (1999), "The Impact of Outsourcing and Hightechnology Capital on Wages: Estimates for The United States, 1979-1990," The Quartely Journal of Economics, August, 907-940.

(1997), "Foreign Direct Investment and Relative

Wages:Evidence from Mexicos maquiladoras," Journal of International Economics 42:371-93.

(1996), "Globalization, Outsourcing, and Wage Inequality," AEA Papers and Proceedings 86(2), 240-245.

Krugman, P. (1995) "Growing World Trade: Causes and Consequences," Brookings Papers on Economic Activity 1, 327-377.

Slaughter, M.J. (1995) "Multinational Corporations, Outsourcing, and American Wage Divergence," Working Paper no.5253, Cambridge, MA.: National Bureau of Economic Research.

(2000), "Production Transfer within Multinational Enterprises and American Wages," Journal of International Economics 50, 449-472

Slaughter, M.J., and Swagel, P. (1997) "The Effect of Globalization on Wages in the Advanced Economies," Working Paper no. 43. Washington, DC: International Monetary Fund. 


\section{Appendix}

$$
\begin{aligned}
& \left(\frac{\hat{W}_{t s}}{W_{m}}\right)=\left((\Omega-1) \frac{\frac{(1-\beta)}{z_{o}} L_{t s}^{o}}{\frac{(1-\beta)}{z_{o}} L_{t s}^{o}+n_{f}}\right) \hat{L}_{t s}+\left((\Omega-1) \frac{n_{f}}{\frac{(1-\beta)}{z_{o}} L_{t s}^{o}+n_{f}}\right) \hat{n}_{f}+\left(\frac{1}{1-\alpha}\right)\left(\frac{\hat{E}}{H}\right) \\
& \left(\frac{\hat{W}_{n t s}}{W_{m}}\right)=\hat{-L}_{n t s}^{o}+\left(\frac{1-\delta}{\delta} \frac{T_{d}^{f}}{\frac{\beta}{(1-\beta)} \frac{z_{p}}{z}-T_{d}^{f}}\right) \hat{T}_{d}^{f}+\left(\frac{1}{\delta}\right) \hat{L}_{m}^{o}-\left(\Omega \frac{1-\delta}{\delta} \frac{\left(\frac{(1-\beta)}{z_{o}}\right) L_{t s}^{o}}{\left(\frac{(1-\beta)}{z_{o}}\right) L_{t s}^{o}+n_{f}}\right) \hat{L}_{t s}^{o} \\
& -\left(\Omega \frac{1-\delta}{\delta} \frac{n_{f}}{\left(\frac{(1-\beta)}{z_{o}}\right) L_{t s}^{o}+n_{f}}\right) \hat{n}_{f}+\left(\frac{1}{(1-\alpha)} \frac{1-\delta}{\delta}\right)\left(\frac{\hat{E}}{H}\right) \\
& \left(\frac{\hat{W}_{t s}}{W_{n t s}}\right)=\hat{L}_{n t s}^{o}\left(\frac{1-\delta}{\delta} \frac{T_{d}^{f}}{\frac{\beta}{(1-\beta)} \frac{z_{o}}{z}-T_{d}^{f}}\right) \hat{T}_{d}^{f}-\left(\frac{1}{\delta}\right) \hat{L}_{m}^{o}+\left((\Omega-1) \frac{\left(\frac{(1-\beta)}{z_{o}}\right) L_{t s}^{o}}{\left(\frac{(1-\beta)}{z_{o}}\right) L_{t s}^{o}+n_{f}}\right. \\
& \cdot\left(\frac{1-\delta}{\delta} \Omega+1\right) \hat{L}_{t s}+\left((\Omega-1) \frac{n_{f}}{\left(\frac{(1-\beta)}{z_{o}}\right) L_{t s}^{o}+n_{f}}\left(\frac{1-\delta}{\delta} \Omega+1\right)\right) \hat{n}_{f}+ \\
& \left(\frac{1}{(1-\alpha)} \frac{1}{\delta}\right)\left(\frac{\hat{E}}{H}\right)
\end{aligned}
$$

where $\delta=1-\left[k^{\frac{1}{1-\alpha}} \frac{(1-\alpha)}{\alpha}\left(\frac{\beta}{(1-\beta)} \frac{z_{o}}{z}-T_{d}^{f}\right) \frac{\left(\frac{(1-\beta) L_{t s}^{o}}{z_{o}}+n_{f}\right)^{\Omega}}{L_{m}^{o}}\right]\left(\frac{H}{E}\right)^{\frac{1}{\alpha-1}}$ 